\title{
Complications associated with the Dynesys dynamic stabilization system: a comprehensive review of the literature
}

\author{
Martin H. Pham, MD, ${ }^{1}$ Vivek A. Mehta, MD, ${ }^{1}$ Neil N. Patel, MD, ${ }^{2}$ Andre M. Jakoi, MD, ${ }^{2}$ \\ Patrick C. Hsieh, MD, ${ }^{1}$ John C. Liu, MD, ${ }^{1}$ Jeffrey C. Wang, MD, ${ }^{2}$ and Frank L. Acosta, MD ${ }^{1}$ \\ Departments of ${ }^{1}$ Neurosurgery and ${ }^{2}$ Orthopedic Surgery, Keck School of Medicine, University of Southern California, Los \\ Angeles, California
}

\begin{abstract}
The Dynesys dynamic stabilization system is an alternative to rigid instrumentation and fusion for the treatment of lumbar degenerative disease. Although many outcomes studies have shown good results, currently lacking is a comprehensive report on complications associated with this system, especially in terms of how it compares with reported complication rates of fusion. For the present study, the authors reviewed the literature to find all studies involving the Dynesys dynamic stabilization system that reported complications or adverse events. Twenty-one studies were included for a total of 1166 patients with a mean age of 55.5 years (range 39-71 years) and a mean follow-up period of 33.7 months (range 12.0-81.6 months). Analysis of these studies demonstrated a surgical-site infection rate of 4.3\%, pedicle screw loosening rate of $11.7 \%$, pedicle screw fracture rate of $1.6 \%$, and adjacent-segment disease (ASD) rate of $7.0 \%$. Of studies reporting revision surgeries, $11.3 \%$ of patients underwent a reoperation. Of patients who developed ASD, 40.6\% underwent a reoperation for treatment. The Dynesys dynamic stabilization system appears to have a fairly similar complication-rate profile compared with published literature on lumbar fusion, and is associated with a slightly lower incidence of ASD.
\end{abstract}

http://thejns.org/doi/abs/10.3171/2015.10.FOCUS15432

KEY WORDS complications; infection; screw loosening; screw fracture; adjacent-segment disease; reoperation; Dynesys

$\mathrm{D}$ YNAMIC stabilization of the spine is a potential alternative to rigid lumbar fusion for lumbar degenerative spinal disease..$^{34,40,41,51,59}$ Recently, a nonfusion stabilization system with motion preservation (Dynesys system, Zimmer Spine) has been explored as an alternative to fusion in an effort to reduce adjacentsegment disease (ASD) and maintain greater physiological movement and function..$^{31,32,47,61}$ Dynesys is a pedicle screw-based dynamic stabilization system that has been used since 1994 and consists of pedicle screws, flexible spacers, and cords. ${ }^{26,41}$ This assembly attempts to neutralize the abnormal forces after surgical intervention at the lumbar spine and maintain a more favorable biomechanical environment for segmental motion., ${ }^{7,62}$ Many follow-up studies have shown good results for a variety of degenerative spinal conditions. . $^{11,27,32,47,55,60,62}$ However, currently lacking is a comprehensive report on complications associated with the implantation of this system.
In this article, we provide a comprehensive review of the literature to identify all reported complications after use of the Dynesys dynamic stabilization system. Knowledge of these events will assist surgeons in maintaining a high index of suspicion with these potential postoperative complications.

\section{Methods}

We conducted a comprehensive review of the Englishlanguage medical literature reported via PubMed (from 1967 to August 16,2015) to find all studies involving use of the Dynesys dynamic stabilization system. Literature was found using the search equation "dynamic neutralization system" OR "dynamic stabilization system" OR "dynesys" OR "dynesis." All resulting articles were reviewed in search of clinical studies that used the Dynesys system and reported complications or adverse events. The refer- 
ence lists of these articles were subsequently reviewed to identify additional English-language studies that may not have been identified by the initial electronic search. Case reports were not included. This search protocol was conducted by 2 reviewers (M.H.P. and V.A.M.).

Articles that met search criteria were further examined for the following parameters: study design, number of patients, age, sex, diagnoses treated, follow-up time, number of levels treated, and all reported complications or adverse events related to implantation of the Dynesys dynamic stabilization system.

\section{Results}

Twenty-three studies were identified, which described use of the Dynesys dynamic stabilization system with a description of subsequent complications. Two studies were excluded because the authors used the same cohort of patients in subsequent studies that were also included in our search results. ${ }^{15,57}$ A total of 21 studies were used for analysis (Table 1). Included in these studies was 1 Executive Summary for the Dynesys system written by the FDA. ${ }^{16}$

Published studies found ranged in publication year from 2002 to 2014. Of these, 9 were prospective studies and 12 were retrospective reviews. There were a total of 1166 patients (568 men and 598 women) with a mean age of 55.5 years (range 39-71 years). The mean follow-up time was 33.7 months (range 12.0-81.6 months). Diagnoses treated included all forms of lumbar degenerative disease, which included but were not limited to degenerative disc disease, discopathy, spinal stenosis, spondylolisthesis, degenerative scoliosis, disc herniation, and ASD. Only 1 study did not report data on number of levels treated with the Dynesys system. ${ }^{22}$ Among all other studies, there was 1-segment stabilization in 509 patients (49.2\%), 2-segment stabilization in 382 patients (36.9\%), 3-segment stabilization in 125 patients (12.1\%), 4-segment stabilization in 12 patients $(1.2 \%), 5$-segment stabilization in 2 patients $(0.2 \%)$, and 6 -segment stabilization in 4 patients $(0.4 \%)$ (Table 2).

\section{Wound Infections}

Thirteen studies specifically mentioned wound-infection rates (Table 3). Among these, 40 of 923 patients (4.3\%) developed wound infections after dynamic stabilization surgery over a mean follow-up period of 34.8 months (range 16.0-81.6 months). These infections included superficial wound infections managed with antibiotic care as well as deep infections requiring reoperation with irrigation and debridement.

\section{Screw Loosening and Fracture}

Fourteen studies described the occurrence of either pedicle screw loosening or pedicle screw fracture after use of the Dynesys system (Table 4). Ninety-six of 822 patients (11.7\%) had pedicle screw loosening and 13 of 822 patients $(1.6 \%)$ had pedicle screw fracture over a mean follow-up period of 30.0 months (range 16.4-54.0 months).

The diagnosis of pedicle screw loosening was not uniform and was not always described in these articles. Several studies clarified their definition of screw loosening by looking for radiolucent zones surrounding the screw on radiographs, which has been previously described as a

TABLE 1. Studies that used the Dynesys system and subsequently described associated complications

\begin{tabular}{llccc}
\hline \multicolumn{1}{c}{ Authors \& Year } & Study Type & No. of Pts (M/F) & Mean Age (yrs) & Mean Follow-Up (mos) \\
\hline Stoll et al., 2002 & Prospective & $83(34: 49)$ & 58.2 & 38.1 \\
\hline Grob et al., 2005 & Retrospective & $31(11: 20)$ & 50.0 & 24.0 \\
\hline Putzier et al., 2005 & Prospective & $35(22: 13)$ & 39.0 & 34.0 \\
\hline Sapkas et al., 2007 & Retrospective & $68(42: 26)$ & 42.8 & 36.2 \\
\hline Bothmann et al., 2008 & Prospective & $54(28: 26)$ & 56.0 & 16.0 \\
\hline Lee et al., 2008 & Retrospective & $20(13: 7)$ & 61.0 & 27.3 \\
\hline Schaeren et al., 2008 & Prospective & $26(8: 18)$ & 71.0 & 52.0 \\
\hline Würgler-Hauri et al., 2008 & Prospective & $37(15: 22)$ & 58.0 & 12.0 \\
\hline FDA, 2009 & Prospective & $253(121: 132)$ & 56.9 & 54.0 \\
\hline Di Silvestre et al., 2010 & Retrospective & $29(7: 22)$ & 68.5 & 16.6 \\
\hline Ko et al., 2010 & Retrospective & $71(32: 39)$ & 59.2 & 16.4 \\
\hline Hu et al., 2011 & Retrospective & $32(19: 13)$ & 58.0 & 43.0 \\
\hline Lutz et al., 2012 & Retrospective & $49(26: 23)$ & 48.0 & 81.6 \\
\hline Sapkas et al., 2012 & Retrospective & $114(66: 48)$ & 49.0 & 36.0 \\
\hline Yu et al., 2012 & Retrospective & $35(15: 20)$ & 60.8 & 48.0 \\
\hline Haddad et al., 2013 & Retrospective & $32(19: 13)$ & 40.6 & 46.7 \\
\hline Fay et al., 2013 & Prospective & $72(37: 35)$ & 61.4 & 30.7 \\
\hline Lee et al., 2014 & Retrospective & $28(7: 21)$ & 65.3 & 20.0 \\
\hline Liu et al., 2014 & Prospective & $37(21: 16)$ & 40.5 & 24.0 \\
\hline Payer et al., 2014 & Prospective & $30(8: 22)$ & 66.0 & 26.6 \\
\hline Yang et al., 2014 & Retrospective & $30(17: 13)$ & 56.0 & \\
\hline Pts = patients. & & & & \\
\hline
\end{tabular}


TABLE 2. Number of patients categorized by number of segments stabilized with Dynesys across all studies

\begin{tabular}{cc}
\hline No. of Segments Stabilized & No. of Pts $(\%)$ \\
\hline 1 & $509(49.2)$ \\
\hline 2 & $382(36.9)$ \\
\hline 3 & $125(12.1)$ \\
\hline 4 & $12(1.2)$ \\
\hline 5 & $2(0.2)$ \\
\hline 6 & $4(0.4)$ \\
\hline
\end{tabular}

"halo sign" or "double-halo sign" signifying screw loosening. 10,34,52,62 Some studies diagnosed screw loosening by a radiologist's interpretation, whereas other studies did not explain their methods.

\section{Adjacent-Segment Disease}

Twelve studies characterized the development of ASD after use of the Dynesys dynamic stabilization system (Table 5). Of a total of 456 patients, 32 (7.0\%) subsequently developed ASD over a mean follow-up period of 33.5 months (range 12-54 months).

\section{Reoperation Rate}

Seventeen articles reported reoperations for various reasons (Table 6). One hundred seventeen of 1032 patients $(11.3 \%)$ required a reoperation over a mean follow-up period of 35.9 months (range 12.0-81.6 months). Indications for repeat surgery included infection, hardware revision, hardware removal, ASD, further decompression, vertebral body fracture, CSF fistula, and epidural hematoma.

Nine studies reported reoperation rates associated with the development of ASD after use of the Dynesys system (Table 7). In these studies, a total of 354 patients were followed over a mean period of 35.7 months. Of the 32 patients who developed ASD, $13(40.6 \%)$ required reoperations for treatment. These 13 revision surgeries constituted

TABLE 3. Studies reporting surgical-site infection rates after use of the Dynesys system

\begin{tabular}{lcc}
\hline \multicolumn{1}{c}{ Authors \& Year } & Total No. of Pts & No. of Pts w/ SSI \\
\hline Stoll et al., 2002 & 83 & 1 \\
\hline Grob et al., 2005 & 31 & 1 \\
\hline Putzier et al., 2005 & 35 & 1 \\
\hline Sapkas et al., 2007 & 68 & 1 \\
\hline Bothmann et al., 2008 & 54 & 1 \\
\hline FDA, 2009 & 253 & 19 \\
\hline Ko et al., 2010 & 71 & 0 \\
\hline Lutz et al., 2012 & 49 & 11 \\
\hline Sapkas et al., 2012 & 114 & 2 \\
\hline Yu et al., 2012 & 35 & 1 \\
\hline Fay et al., 2013 & 72 & 0 \\
\hline Lee et al., 2014 & 28 & 2 \\
\hline Yang et al., 2014 & 30 & 0 \\
\hline
\end{tabular}

SSI = surgical-site infection.
TABLE 4. Studies reporting pedicle screw loosening or fracture after use of the Dynesys system

\begin{tabular}{lccc}
\hline \multicolumn{1}{c}{ Authors \& Year } & $\begin{array}{c}\text { Total } \\
\text { No. of } \\
\text { Pts }\end{array}$ & $\begin{array}{c}\text { No. of Pts } \\
\text { w/ Screw } \\
\text { Loosening }\end{array}$ & $\begin{array}{c}\text { No. of Pts } \\
\text { w/ Screw } \\
\text { Fracture }\end{array}$ \\
\hline Stoll et al., 2002 & 83 & 7 & 0 \\
\hline Putzier et al., 2005 & 35 & 0 & 0 \\
\hline Sapkas et al., 2007 & 68 & 3 & 0 \\
\hline Bothmann et al., 2008 & 54 & 7 & 1 \\
\hline Lee et al., 2008 & 20 & 0 & 0 \\
\hline Schaeren et al., 2008 & 26 & 3 & 1 \\
\hline Würgler-Hauri et al., 2008 & 37 & 0 & 3 \\
\hline FDA, 2009 & 253 & 18 & 6 \\
\hline Di Silvestre et al., 2010 & 29 & 4 & 0 \\
\hline Ko et al., 2010 & 71 & 14 & 0 \\
\hline Hu et al., 2011 & 32 & 0 & 0 \\
\hline Lutz et al., 2012 & 49 & 36 & 2 \\
\hline Lee et al., 2014 & 28 & 4 & 0 \\
\hline Liu et al., 2014 & 37 & 0 & 0 \\
\hline
\end{tabular}

part of a total of 57 reported reoperations for any indication in this group.

\section{Discussion}

Dynamic stabilization as an alternative to fusion offers several advantages. These include stabilization of spinal segments without instrumentation and fusion, unloading at the motion segment of the disc and facet joints, and greater preservation of physiological function. . $^{31,32,47,61}$ With regard to this article, however, it is important to note that the Dynesys system has only received US FDA approval for use as an adjunct to spinal fusion. Although commonly used as a nonfusion implant, placement of this system for the purposes of dynamic stabilization is an off-label use in the US.

Recent publications have shown that use of the Dynesys system as a nonfusion pedicle screw stabilization

TABLE 5. Studies reporting the development of ASD after use of the Dynesys system

\begin{tabular}{lcc}
\hline \multicolumn{1}{c}{ Authors \& Year } & Total No. of Pts & No. of Pts w/ ASD \\
\hline Stoll et al., 2002 & 83 & 7 \\
\hline Putzier et al., 2005 & 35 & 0 \\
\hline Bothmann et al., 2008 & 54 & 3 \\
\hline Lee et al., 2008 & 20 & 0 \\
\hline Schaeren et al., 2008 & 26 & 9 \\
\hline Di Silvestre et al., 2010 & 29 & 1 \\
\hline Lutz et al., 2012 & 49 & 1 \\
\hline Yu et al., 2012 & 35 & 6 \\
\hline Lee et al., 2014 & 28 & 2 \\
\hline Liu et al., 2014 & 37 & 0 \\
\hline Payer et al., 2014 & 30 & 3 \\
\hline Yang et al., 2014 & 30 & 0 \\
\hline
\end{tabular}


TABLE 6. Studies reporting reoperations after use of the Dynesys system

\begin{tabular}{|c|c|c|c|}
\hline Authors \& Year & Total No. of Pts & No. of Pts Undergoing Reop & Described Reasons for Reop (no. of instances) \\
\hline Stoll et al., 2002 & 83 & 17 & $\begin{array}{l}\text { Not mutually exclusive: "dural lesion" (1); paresis requiring revision \& } \\
\text { extension (1); drainage of seroma (1); excision of neuroma scar (1); } \\
\text { revision of screw malposition (1); screw loosening causing symptoms } \\
\text { (1); complete implant removal (8); Dynesys extension (2); decompres- } \\
\text { sion of adjacent segment (2); laminectomy of index segment (1); ASD } \\
\text { (7) }\end{array}$ \\
\hline Grob et al., 2005 & 31 & 8 & Removal of device (3); removal \& fusion (4); infection (1) \\
\hline Sapkas et al., 2007 & 68 & 2 & $\begin{array}{l}\text { Infection w/ removal \& fusion (1); persistent leg pain w/ removal \& fusion } \\
\text { (1) }\end{array}$ \\
\hline Bothmann et al., 2008 & 54 & 11 & $\begin{array}{l}\text { Not mutually exclusive: bilat partial pedicle fracture \& hardware loosen- } \\
\text { ing (1); screw fracture (1); screw loosening (7); infection (1); Dynesys } \\
\text { extension (1); decompression of adjacent segment (1); adjacent- } \\
\text { segment instability (3) }\end{array}$ \\
\hline Lee et al., 2008 & 20 & 3 & $\begin{array}{l}\text { Implant removal for allergic reaction (1); further decompression (1); } \\
\text { further decompression \& fusion (1) }\end{array}$ \\
\hline Schaeren et al., 2008 & 26 & 4 & $\begin{array}{l}\text { Further decompression (1); osteoporotic fracture at index level (2); ASD } \\
\text { (1) }\end{array}$ \\
\hline Würgler-Hauri et al., 2008 & 37 & 7 & $\begin{array}{l}\text { Removal w/ fusion (4); replacement of misplaced screws (2); repair of } \\
\text { CSF fistula (1) }\end{array}$ \\
\hline FDA, 2009 & 253 & 33 & $\begin{array}{l}\text { Reasons for revision surgeries: additional decompression, removal of } \\
\text { hardware w/ fusion, infection, ASD, epidural hematoma }\end{array}$ \\
\hline Di Silvestre et al., 2010 & 29 & 2 & Replacement of misplaced screw (1); ASD (1) \\
\hline Ko et al., 2010 & 71 & 0 & \\
\hline Lutz et al., 2012 & 49 & 17 & $\begin{array}{l}\text { Infection (10); screw fracture \& infection (1); screw fracture (1); screw } \\
\text { revision (1); screw loosening w/ migration (1); instability (1); nerve root } \\
\text { compression (1); ASD (1) }\end{array}$ \\
\hline Sapkas et al., 2012 & 114 & 6 & Screw loosening (3); infection w/ fusion (2); implant removal (1) \\
\hline Yu et al., 2012 & 35 & 0 & \\
\hline Haddad et al., 2013 & 32 & 4 & $\begin{array}{l}\text { Reasons for revision surgeries: persistent symptoms, malpositioning of } \\
\text { screws, symptomatic screw loosening }\end{array}$ \\
\hline Fay et al., 2013 & 72 & 0 & \\
\hline Lee et al., 2014 & 28 & 2 & Infection (2) \\
\hline Payer et al., 2014 & 30 & 1 & ASD (1) \\
\hline
\end{tabular}

construct has favorable outcomes with shorter hospital stays compared with spinal fusion. , $, 8,18,24,46,53,58,62,67,70$ This stabilization system also reportedly provides enough stability to prevent progression of low-grade spondylolistheses. ${ }^{27,55,57,62}$ The maintenance of biomechanical mobility in the lumbar spine plays a significant role in patient quality of life, and dynamic stabilization helps to maintain this mobility. ${ }^{18,47,53,58,62}$ Without the need for fusion, there are no risks of bone graft donor-site complications such as pain, hematoma, or fracture. No allograft materials are required, also preventing the already low risk of disease transmission associated with these products. ${ }^{45,55,67,71}$ However, the Dynesys system is not without its own set of complications and adverse events, which we aimed to characterize with this review.

Postoperative surgical-site infection is a significant complication that can progress to further morbidity. $\mathrm{Pa}-$ tients with infections have worse pain-related outcomes, increased deformity, higher medical costs, and longer hospital stays. $3,6,19,39$ We found an overall reported infection rate of $4.3 \%$ over a mean follow-up period of 34.8 months in this review of studies in which the Dynesys dynamic stabilization system was used. This is similar to the reported literature on infection rates for lumbar fusion, which range from $1 \%$ to $5 \% .^{6,14,42,43,66}$ Chaichana et al. recently reviewed their experience with 817 consecutive patients who underwent posterior instrumented lumbar fusion specifically for degenerative spine disease. ${ }^{6}$ They found that 37 patients (4.5\%) developed a postoperative infection that was diagnosed at a median of 0.6 months after surgery. Twenty-one patients $(57 \%)$ required reoperation for incision, drainage, and/or debridement. They found that age greater than 70 years, diabetes, obesity, previous spinal surgery, and a hospital stay of more than 7 days were independently associated with an increased risk of infection.

In this comprehensive review, 13 studies specifically mentioned the occurrence or absence of postoperative surgical-site infection. We did not count studies that were vague or did not address infection as a complication. However, several articles did comment on a general lack of complications in their patient groups, although they did not specifically state a lack of wound infections. ${ }^{11,24,33} \mathrm{It}$ 
TABLE 7. Studies reporting reoperation rates for ASD after use of the Dynesys system

\begin{tabular}{lccc}
\hline \multicolumn{1}{c}{ Authors \& Year } & $\begin{array}{c}\text { Total No. } \\
\text { of Pts }\end{array}$ & $\begin{array}{c}\text { No. of } \\
\text { Pts w/ } \\
\text { ASD }\end{array}$ & $\begin{array}{c}\text { No. of Pts } \\
\text { Undergoing Reop } \\
\text { for ASD }\end{array}$ \\
\hline Stoll et al., 2002 & 83 & 7 & 7 \\
\hline Bothmann et al., 2008 & 54 & 3 & 3 \\
\hline Lee et al., 2008 & 20 & 0 & 0 \\
\hline Schaeren et al., 2008 & 26 & 9 & 1 \\
\hline Di Silvestre et al., 2010 & 29 & 1 & 1 \\
\hline Lutz et al., 2012 & 49 & 1 & 1 \\
\hline Yu et al., 2012 & 35 & 6 & 0 \\
\hline Lee et al., 2014 & 28 & 2 & 0 \\
\hline Payer et al., 2014 & 30 & 3 & 1 \\
\hline
\end{tabular}

is possible that our finding of a $4.3 \%$ infection rate may overestimate the true risk of infection by excluding studies that had no infection rates.

Because there is no rigid fusion, the long-term repetitive demands on construct durability and mechanical strength are higher for the Dynesys system. This manifests itself through pedicle screw loosening and fracture, suggesting an abnormal range of motion in the stabilized lumbar spine segments that is higher than expected. ${ }^{27} \mathrm{Da}-$ khil-Jerew et al. described the findings of a "halo zone" and "double-halo zones" to diagnose loose pedicle screws in dynamic stabilization systems based on plain radiographs..$^{10}$ Although several studies reported identification of screw loosening via these techniques, articles were not always uniform in describing how they arrived at the finding of a loose screw. Also, 8 studies were published before the description of the halo zone to assist in the diagnosis of this complication. $5,21,32,47,54,55,62,68$

We found that $11.7 \%$ of patients developed pedicle screw loosening and $1.6 \%$ of patients were found to have a pedicle screw fracture over a mean follow-up period of 30.0 months. Our screw fracture rate of $1.6 \%$ is on the lower end of reported screw breakages for lumbar fusion, which are reported from $1.3 \%$ to $21 \%$ but are mostly within the 4\%-6\% range. ${ }^{12,13,38,63,69,72}$ These results suggest that the Dynesys system offers more biomechanical flexibility than rigid instrumented fusion constructs, which minimizes the incidence of broken screws. ${ }^{27,56}$ This flexibility, however, may be the cause of screw loosening, which was found in a significant number of patients.

Although the radiographic finding of screw loosening can be problematic, some studies have shown that overall outcomes are similar regardless of screw issues. Ko et al. found similar results on the visual analog scale for low-back pain and the Oswestry Disability Index for functional disability, regardless of screw loosening, in their group of 71 patients. ${ }^{27}$ They concluded that the loosening of screws had no adverse effect on clinical improvement. Similarly, Schaeren et al. noted that their patients did not experience any symptoms or back pain with screw fractures or loosening. ${ }^{55}$ In contrast, Bothmann et al. believed that persistent back and leg symptoms in their 7 patients with screw loosening could be attributed to the hardware, and all patients underwent revision surgery. ${ }^{5}$ Other studies have also described symptomatic screw loosening that required reoperation for revision or removal of the hardware. $22,34,53,62$

Lutz et al. reported by far the highest rate of screw loosening in 36 of their 49 patients $(73.5 \%)$ compared with all other reporting studies, for which the average was 60 of 773 patients $(7.8 \%) .{ }^{34}$ Lutz and colleagues diagnosed their loose screws using single- or double-halo zones on followup radiographs of patients operated on between May 2002 and September 2008 with a mean follow-up of 43 months. They hypothesized that the high rate of screw loosening was possibly due to poor integration at the bone-screw interface due to biomechanical screw design. They stated that since their study was done, hydroxyapatite-coated screws have been developed to achieve better osseointegration, which may reduce the risk of screw loosening in future patients.

One of the goals of the Dynesys system is to avoid ASD by using dynamic stabilization to reduce biomechanical stress on segments adjacent to the index stabilized levels. ${ }^{17,55}$ ASD is a significant complication of lumbar spine surgery that theoretically occurs due to an overloading of these adjacent segments.,50 Unfortunately, this term is vague and it is often unclear in the general literature if the reported ASD pathology was diagnosed purely by radiographic criteria or if there was a correlated clinical effect. Lawrence et al. proposed the use of an umbrella term, adjacent-segment pathology (ASP), under which radiographic ASP and clinical ASP could then categorize radiographic findings of degenerative changes versus clinical manifestations that correlate with radiographs, respectively. ${ }^{30}$ In this manner, patients with ASD who present with pain, radiculopathy, or myelopathy could be studied specifically to determine ideal treatment algorithms based on outcomes, without the dilution of clinically silent ASD. Many studies in this review, however, did not expand upon their definition of ASD; therefore, the actual number of patients who presented with clinical symptoms is unclear.

In this review of Dynesys dynamic stabilization, we found that ASD developed in $7 \%$ of patients over a mean follow-up period of 33.5 months. This seems to be on the lower end of the range when compared with the reported incidences of ASD in lumbar fusion, but these incidences are also highly variable. A systematic review by Park et al. on ASD of the lumbar spine after lumbar fusion found the incidence of radiographically diagnosed ASD to be from $8 \%$ to $100 \%$, whereas in studies focusing on clinically symptomatic ASD the incidence ranged from $5.2 \%$ to $18.5 \% .{ }^{44}$ Radcliff et al. reviewed the literature and found ASD rates after lumbar fusion in noncontrolled cohort studies to be between $1.9 \%$ and $30.3 \%$ at 5 years, with the largest study reporting $13 \%$ at 5 years and $22 \%$ at 10 years, with a mean annual incidence of $2.5 \% .{ }^{49}$ Another recent review, which performed survival analyses, determined that clinically relevant ASD occurred at a mean annual incidence of $0.6 \%-3.9 \%$ after lumbar fusion. ${ }^{30}$

It is possible that the Dynesys system allows for enough physiological motion to spare abnormal biomechanical stress at adjacent segments after stabilization. Nevertheless, several studies in our review reported fairly high rates 
of ASD. In their retrospective review, Yu et al. found that 6 of their 35 patients $(17.1 \%)$ developed ASD..$^{71}$ Schaeren et al. reported an even higher incidence of $47 \%$ when including only those patients who completed the full 4-year follow-up in their prospective series. ${ }^{55}$ Despite the intent of a nonfusion dynamic stabilization system, the Dynesys construct may have high enough intrinsic stability that it acts similarly enough to fusion to overload the adjacent segments. ${ }^{2,55,56}$

It remains unclear whether adjacent-segment degeneration is due to the increased biomechanical stress of instrumented surgery or if it is simply a manifestation of the natural history of the degenerated lumbar spine. Nevertheless, the development of ASD may not be clinically relevant over the long term. A recent study by Mannion et al. reviewed long-term follow-up from 4 randomized controlled trials to examine the effect of ASD on patient self-rated outcomes. ${ }^{36}$ Over a mean follow-up period of 13 years, they found no correlation of adjacent-level disc-space height with Oswestry Disability Index or pain scores. This finding would dampen the presumed benefits of dynamic stabilization in its expected reduction of ASD if the adjacent degeneration has no significant clinical effect.

Of a total of 1032 patients in 17 studies that reported revision surgeries, we found that 117 patients (11.3\%) underwent a reoperation. Of patients who developed ASD, $40.6 \%$ were reported to have had a reoperation for this complication. The majority of other reoperations were for infection, hardware revision, or hardware removal, often with subsequent instrumentation and fusion. This is fairly consistent with reoperation rates in lumbar fusion reported in the literature. Radcliff et al. performed a subgroup analysis of the Spine Patient Outcomes Research Trial (SPORT) and found a 13\% reoperation rate within 4 years for patients who had undergone surgery for lumbar spinal stenosis. ${ }^{48}$ For patients with lumbar spondylolisthesis, Lad et al. reviewed 16,556 patients through a database search and found overall reoperation rates ranging from $10.6 \%$ to $18.4 \%$, depending on whether patients underwent decompression alone versus instrumented and uninstrumented arthrodesis. ${ }^{29}$ Many other studies on lumbar fusion have reported similar ranges of reoperation rates. ${ }^{9,20,23,25,28,35,37,64,65}$ This suggests that overall reoperation rates after lumbar spine surgery may be a function of both the presenting diagnosis combined with open surgical intervention at the lumbar spine.

This study has several limitations. The populations of these 21 studies were extremely diverse in terms of age, sex, diagnosis, and number of levels treated. The indications for surgery spanned the breadth of lumbar degenerative disease, for which the overall outcomes and complication rates may differ among specific diagnoses such as spinal stenosis, spondylolisthesis, degenerative scoliosis, or disc herniation. Many of the surgical case series we found were retrospective reviews, in which there inherently may be some bias. The information available to us from the articles reviewed was not always complete. Furthermore, the way that studies defined infection, screw loosening, or ASD was not always provided. As mentioned previously, if studies stated a general lack of complications but did not specifically state which complications they had reviewed, they were excluded from our analysis. Despite these limitations, we think the information gleaned through this comprehensive review is able to put into perspective complication rates associated with implantation of the Dynesys dynamic stabilization system. Dynesys, and other similar stabilization systems, need further studies to determine their true utility and associated risks and benefits.

\section{Conclusions}

The Dynesys system was developed as an alternative to rigid instrumentation and fusion constructs. A review of complications associated with this system found similar infection rates and reoperation rates when compared with published literature on lumbar fusion. There was a higher incidence of pedicle screw loosening although there was a lower incidence of screw fractures, the former probably due to the long-term repetitive demands on nonrigid hardware. The overall incidence of ASD appeared to be lower than that of many published rates after lumbar fusion, which may support an offloading of biomechanical stress at the adjacent segment.

\section{References}

1. Aota Y, Kumano K, Hirabayashi S: Postfusion instability at the adjacent segments after rigid pedicle screw fixation for degenerative lumbar spinal disorders. J Spinal Disord 8:464-473, 1995

2. Beastall J, Karadimas E, Siddiqui M, Nicol M, Hughes J, Smith F, et al: The Dynesys lumbar spinal stabilization system: a preliminary report on positional magnetic resonance imaging findings. Spine (Phila Pa 1976) 32:685-690, 2007

3. Bible JE, Biswas D, Devin CJ: Postoperative infections of the spine. Am J Orthop 40:E264-E271, 2011

4. Bordes-Monmeneu M, Bordes-Garcia V, Rodrigo-Baeza F, Saez D: [System of dynamic neutralization in the lumbar spine: experience on 94 cases.] Neurocirugia (Astur) 16:499-506, 2005 (Span)

5. Bothmann M, Kast E, Boldt GJ, Oberle J: Dynesys fixation for lumbar spine degeneration. Neurosurg Rev 31:189-196, 2008

6. Chaichana KL, Bydon M, Santiago-Dieppa DR, Hwang L, McLoughlin G, Sciubba DM, et al: Risk of infection following posterior instrumented lumbar fusion for degenerative spine disease in 817 consecutive cases. J Neurosurg Spine 20:45-52, 2014

7. Cho MJ, Chung CK, Kim CH: Screw loosening and migration after Dynesys implantation. Korean J Spine 9:300-303, 2012

8. Cienciala J, Chaloupka R, Repko M, Krbec M: [Dynamic neutralization using the Dynesys system for treatment of degenerative disc disease of the lumbar spine.] Acta Chir Orthop Traumatol Cech 77:203-208, 2010 (Czech)

9. Ciol MA, Deyo RA, Kreuter W, Bigos SJ: Characteristics in Medicare beneficiaries associated with reoperation after lumbar spine surgery. Spine (Phila Pa 1976) 19:1329-1334, 1994

10. Dakhil-Jerew F, Jadeja H, Cohen A, Shepperd JA: Interobserver reliability of detecting Dynesys pedicle screw using plain X-rays: a study on 50 post-operative patients. Eur Spine J 18:1486-1493, 2009

11. Di Silvestre M, Lolli F, Bakaloudis G, Parisini P: Dynamic stabilization for degenerative lumbar scoliosis in elderly patients. Spine (Phila Pa 1976) 35:227-234, 2010

12. Dickman CA, Fessler RG, MacMillan M, Haid RW: Transpedicular screw-rod fixation of the lumbar spine: operative 
technique and outcome in 104 cases. J Neurosurg 77:860870, 1992

13. Esses SI, Sachs BL, Dreyzin V: Complications associated with the technique of pedicle screw fixation. A selected survey of ABS members. Spine (Phila Pa 1976) 18:2231-2239, 1993

14. Fang A, Hu SS, Endres N, Bradford DS: Risk factors for infection after spinal surgery. Spine (Phila Pa 1976) 30:14601465,2005

15. Fay LY, Wu JC, Tsai TY, Wu CL, Huang WC, Cheng H: Dynamic stabilization for degenerative spondylolisthesis: evaluation of radiographic and clinical outcomes. Clin Neurol Neurosurg 115:535-541, 2013

16. Food and Drug Administration: Executive Summary for Zimmer Spine's Dynesys Spinal System, Washington, DC: Food and Drug Administration, 2009

17. Freudiger S, Dubois G, Lorrain M: Dynamic neutralisation of the lumbar spine confirmed on a new lumbar spine simulator in vitro. Arch Orthop Trauma Surg 119:127-132, 1999

18. Fritzell P, Hägg O, Wessberg P, Nordwall A: Chronic low back pain and fusion: a comparison of three surgical techniques: a prospective multicenter randomized study from the Swedish lumbar spine study group. Spine (Phila Pa 1976) 27:1131-1141, 2002

19. Gerometta A, Rodriguez Olaverri JC, Bitan F: Infections in spinal instrumentation. Int Orthop 36:457-464, 2012

20. Ghiselli G, Wang JC, Bhatia NN, Hsu WK, Dawson EG: Adjacent segment degeneration in the lumbar spine. J Bone Joint Surg Am 86-A:1497-1503, 2004

21. Grob D, Benini A, Junge A, Mannion AF: Clinical experience with the Dynesys semirigid fixation system for the lumbar spine: surgical and patient-oriented outcome in 50 cases after an average of 2 years. Spine (Phila Pa 1976) 30:324-331, 2005

22. Haddad B, Makki D, Konan S, Park D, Khan W, Okafor B: Dynesys dynamic stabilization: less good outcome than lumbar fusion at 4-year follow-up. Acta Orthop Belg 79:97-103, 2013

23. Hu RW, Jaglal S, Axcell T, Anderson G: A population-based study of reoperations after back surgery. Spine (Phila Pa 1976) 22:2265-2271, 1997

24. Hu Y, Gu YJ, Xu RM, Zhou LJ, Ma WH: Short-term clinical observation of the Dynesys neutralization system for the treatment of degenerative disease of the lumbar vertebrae. Orthop Surg 3:167-175, 2011

25. Jansson KA, Németh G, Granath F, Blomqvist P: Spinal stenosis re-operation rate in Sweden is $11 \%$ at 10 years-a national analysis of 9,664 operations. Eur Spine J 14:659-663, 2005

26. Kim CH, Chung CK, Jahng TA: Comparisons of outcomes after single or multilevel dynamic stabilization: effects on adjacent segment. J Spinal Disord Tech 24:60-67, 2011

27. Ko CC, Tsai HW, Huang WC, Wu JC, Chen YC, Shih YH, et al: Screw loosening in the Dynesys stabilization system: radiographic evidence and effect on outcomes. Neurosurg Focus 28(6):E10, 2010

28. Kornblum MB, Fischgrund JS, Herkowitz HN, Abraham DA, Berkower DL, Ditkoff JS: Degenerative lumbar spondylolisthesis with spinal stenosis: a prospective long-term study comparing fusion and pseudarthrosis. Spine (Phila Pa 1976) 29:726-734, 2004

29. Lad SP, Babu R, Baker AA, Ugiliweneza B, Kong M, Bagley $\mathrm{CA}$, et al: Complications, reoperation rates, and health-care cost following surgical treatment of lumbar spondylolisthesis. J Bone Joint Surg Am 95:e162, 2013

30. Lawrence BD, Wang J, Arnold PM, Hermsmeyer J, Norvell DC, Brodke DS: Predicting the risk of adjacent segment pathology after lumbar fusion: a systematic review. Spine (Phila Pa 1976) 37 (22 Suppl):S123-S132, 2012
31. Lee SE, Jahng TA, Kim HJ: Decompression and nonfusion dynamic stabilization for spinal stenosis with degenerative lumbar scoliosis: Clinical article. J Neurosurg Spine 21:585-594, 2014

32. Lee SE, Park SB, Jahng TA, Chung CK, Kim HJ: Clinical experience of the dynamic stabilization system for the degenerative spine disease. J Korean Neurosurg Soc 43:221-226, 2008

33. Liu C, Wang L, Tian JW: Early clinical effects of the Dynesys system plus transfacet decompression through the Wiltse approach for the treatment of lumbar degenerative diseases. Med Sci Monit 20:853-859, 2014

34. Lutz JA, Otten P, Maestretti G: Late infections after dynamic stabilization of the lumbar spine with Dynesys. Eur Spine J 21:2573-2579, 2012

35. Malter AD, McNeney B, Loeser JD, Deyo RA: 5-year reoperation rates after different types of lumbar spine surgery. Spine (Phila Pa 1976) 23:814-820, 1998

36. Mannion AF, Leivseth G, Brox JI, Fritzell P, Hägg O, Fairbank JC: ISSLS Prize winner: Long-term follow-up suggests spinal fusion is associated with increased adjacent segment disc degeneration but without influence on clinical outcome: results of a combined follow-up from 4 randomized controlled trials. Spine (Phila Pa 1976) 39:1373-1383, 2014

37. Martin BI, Mirza SK, Comstock BA, Gray DT, Kreuter W, Deyo RA: Reoperation rates following lumbar spine surgery and the influence of spinal fusion procedures. Spine (Phila Pa 1976) 32:382-387, 2007

38. Matsuzaki H, Tokuhashi Y, Matsumoto F, Hoshino M, Kiuchi T, Toriyama S: Problems and solutions of pedicle screw plate fixation of lumbar spine. Spine (Phila Pa 1976) 15:11591165,1990

39. Meredith DS, Kepler CK, Huang RC, Brause BD, BoachieAdjei O: Postoperative infections of the lumbar spine: presentation and management. Int Orthop 36:439-444, 2012

40. Mulholland RC: The myth of lumbar instability: the importance of abnormal loading as a cause of low back pain. Eur Spine J 17:619-625, 2008

41. Mulholland RC, Sengupta DK: Rationale, principles and experimental evaluation of the concept of soft stabilization. Eur Spine J 11 (Suppl 2):S198-S205, 2002

42. Olsen MA, Mayfield J, Lauryssen C, Polish LB, Jones M, Vest J, et al: Risk factors for surgical site infection in spinal surgery. J Neurosurg 98 (2 Suppl):149-155, 2003

43. Olsen MA, Nepple JJ, Riew KD, Lenke LG, Bridwell KH, Mayfield J, et al: Risk factors for surgical site infection following orthopaedic spinal operations. J Bone Joint Surg Am 90:62-69, 2008

44. Park P, Garton HJ, Gala VC, Hoff JT, McGillicuddy JE: Adjacent segment disease after lumbar or lumbosacral fusion: review of the literature. Spine (Phila Pa 1976) 29:19381944, 2004

45. Payer M, Smoll NR, Oezkan N, Tessitore E: Dynamic transpedicular stabilisation and decompression in single-level degenerative anterolisthesis and stenosis. Acta Neurochir (Wien) 156:221-227, 2014 [Erratum in Acta Neurochir (Wien) 156:759, 2014]

46. Putzier M, Schneider SV, Funk J, Perka C: [Application of a dynamic pedicle screw system (DYNESYS) for lumbar segmental degenerations - comparison of clinical and radiological results for different indications.] Z Orthop Ihre Grenzgeb 142:166-173, 2004 (Ger)

47. Putzier M, Schneider SV, Funk JF, Tohtz SW, Perka C: The surgical treatment of the lumbar disc prolapse: nucleotomy with additional transpedicular dynamic stabilization versus nucleotomy alone. Spine (Phila Pa 1976) 30:E109-E114, 2005

48. Radcliff K, Curry P, Hilibrand A, Kepler C, Lurie J, Zhao W, et al: Risk for adjacent segment and same segment reopera- 
tion after surgery for lumbar stenosis: a subgroup analysis of the Spine Patient Outcomes Research Trial (SPORT). Spine (Phila Pa 1976) 38:531-539, 2013

49. Radcliff KE, Kepler CK, Jakoi A, Sidhu GS, Rihn J, Vaccaro AR, et al: Adjacent segment disease in the lumbar spine following different treatment interventions. Spine J 13:13391349,2013

50. Rahm MD, Hall BB: Adjacent-segment degeneration after lumbar fusion with instrumentation: a retrospective study. $\mathbf{J}$ Spinal Disord 9:392-400, 1996

51. Reyes-Sánchez A, Zárate-Kalfópulos B, Ramírez-Mora I, Rosales-Olivarez LM, Alpizar-Aguirre A, Sánchez-Bringas G: Posterior dynamic stabilization of the lumbar spine with the Accuflex rod system as a stand-alone device: experience in 20 patients with 2-year follow-up. Eur Spine J 19:21642170,2010

52. Sandén B, Olerud C, Petrén-Mallmin M, Johansson C, Larsson $\mathrm{S}$ : The significance of radiolucent zones surrounding pedicle screws. Definition of screw loosening in spinal instrumentation. J Bone Joint Surg Br 86:457-461, 2004

53. Sapkas G, Mavrogenis AF, Starantzis KA, Soultanis K, Kokkalis ZT, Papagelopoulos PJ: Outcome of a dynamic neutralization system for the spine. Orthopedics 35:e1497-e1502, 2012

54. Sapkas GS, Themistocleous GS, Mavrogenis AF, Benetos IS, Metaxas N, Papagelopoulos PJ: Stabilization of the lumbar spine using the dynamic neutralization system. Orthopedics 30:859-865, 2007

55. Schaeren S, Broger I, Jeanneret B: Minimum four-year follow-up of spinal stenosis with degenerative spondylolisthesis treated with decompression and dynamic stabilization. Spine (Phila Pa 1976) 33:E636-E642, 2008

56. Schmoelz W, Huber JF, Nydegger T, Dipl-Ing, Claes L, Wilke HJ: Dynamic stabilization of the lumbar spine and its effects on adjacent segments: an in vitro experiment. J Spinal Disord Tech 16:418-423, 2003

57. Schnake KJ, Schaeren S, Jeanneret B: Dynamic stabilization in addition to decompression for lumbar spinal stenosis with degenerative spondylolisthesis. Spine (Phila Pa 1976) 31:442-449, 2006

58. Schwarzenbach O, Berlemann U: [Dynamic posterior stabilization with the pedicle screw system DYNESYS ${ }^{\circledR}$.] Oper Orthop Traumatol 22:545-557, 2010 (Ger)

59. Schwarzenbach O, Berlemann U, Stoll TM, Dubois G: Posterior dynamic stabilization systems: DYNESYS. Orthop Clin North Am 36:363-372, 2005

60. Schwarzenbach O, Rohrbach N, Berlemann U: Segment-bysegment stabilization for degenerative disc disease: a hybrid technique. Eur Spine J 19:1010-1020, 2010

61. Sengupta DK: Point of view: Dynamic stabilization in addition to decompression for lumbar spinal stenosis with degenerative spondylolisthesis. Spine (Phila Pa 1976) 31:450, 2006

62. Stoll TM, Dubois G, Schwarzenbach O: The dynamic neutralization system for the spine: a multi-center study of a novel non-fusion system. Eur Spine J 11 (Suppl 2):S170-S178, 2002

63. Suda K, Ito M, Abumi K, Haba H, Taneichi H, Kaneda K: Radiological risk factors of pseudoarthrosis and/or instrument breakage after PLF with the pedicle screw system in isthmic spondylolisthesis. J Spinal Disord Tech 19:541-546, 2006

64. Taylor VM, Deyo RA, Ciol M, Kreuter W: Surgical treatment of patients with back problems covered by workers compensation versus those with other sources of payment. Spine (Phila Pa 1976) 21:2255-2259, 1996

65. Taylor VM, Deyo RA, Goldberg H, Ciol M, Kreuter W, Spunt B: Low back pain hospitalization in Washington State: recent trends and geographic variations. J Spinal Disord 8:1-7, 1995

66. Weinstein MA, McCabe JP, Cammisa FP Jr: Postoperative spinal wound infection: a review of 2,391 consecutive index procedures. J Spinal Disord 13:422-426, 2000

67. Welch WC, Cheng BC, Awad TE, Davis R, Maxwell JH, Delamarter R, et al: Clinical outcomes of the Dynesys dynamic neutralization system: 1-year preliminary results. Neurosurg Focus 22(1):E8, 2007

68. Würgler-Hauri CC, Kalbarczyk A, Wiesli M, Landolt H, Fandino J: Dynamic neutralization of the lumbar spine after microsurgical decompression in acquired lumbar spinal stenosis and segmental instability. Spine (Phila Pa 1976) 33:E66-E72, 2008

69. Yahiro MA: Comprehensive literature review. Pedicle screw fixation devices. Spine (Phila Pa 1976) 19 (20 Suppl):2274S-2278S, 1994

70. Yang M, Li C, Chen Z, Bai Y, Li M: Short term outcome of posterior dynamic stabilization system in degenerative lumbar diseases. Indian J Orthop 48:574-581, 2014

71. Yu SW, Yang SC, Ma CH, Wu CH, Yen CY, Tu YK: Comparison of Dynesys posterior stabilization and posterior lumbar interbody fusion for spinal stenosis L4L5. Acta Orthop Belg 78:230-239, 2012

72. Yuan HA, Garfin SR, Dickman CA, Mardjetko SM: A historical cohort study of pedicle screw fixation in thoracic, lumbar, and sacral spinal fusions. Spine (Phila Pa 1976) 19 (20 Suppl):2279S-2296S, 1994

\section{Disclosures}

Dr. Acosta is a consultant for NuVasive. Dr. Liu receives travel support from AOSpine. Dr. Wang receives royalties from Stryker, Osprey, Biomet, Synthes, Seaspine, Amedica, and Aesculap. Dr. Wang holds investments or options in Bone Biologics, Alphatech, Axiomed, Amedica, Corespine, Expanding Ortho, Pioneer, Axis, Syndicom, VG Innovations, Pearldiver, Flexuspine, Fziomed, Benvenue, Promethean, Nexgen, Electrocore, and Surgitech. Dr. Wang is on the board of directors of NASS, NASF, CSRS, AOSpine, and CSRF. Dr. Wang is on the editorial board of directors of Spine, JAAOS, The Spine Journal, Journal of Spinal Disorders and Techniques, Global Spine Journal, and The Journal of Orthopaedic Trauma. Dr. Wang's institution receives fellowship funding from AOSpine. Dr. Hsieh is a consultant for DePuy Synthes, Medtronic, and Siemens.

\section{Author Contributions}

Conception and design: Pham. Acquisition of data: Pham, Mehta. Analysis and interpretation of data: Pham, Mehta. Drafting the article: Pham, Mehta, Patel, Jakoi. Critically revising the article: all authors. Reviewed submitted version of manuscript: all authors. Study supervision: Acosta.

\section{Correspondence}

Martin H. Pham, LAC+USC Medical Center, 1200 N. State St., Ste. 3300, Los Angeles, CA 90089. email: martin.pham@usc.edu. 